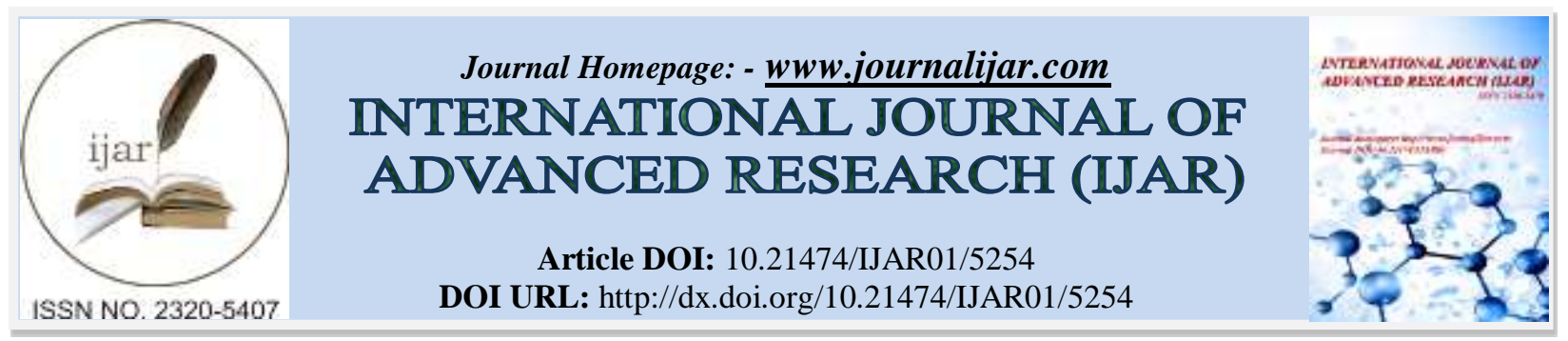

RESEARCH ARTICLE

\title{
REGULAR MILDLY GENERALIZED CLOSED AND REGULAR MILDLY GENERALIZED OPEN MAPS IN TOPOLOGICAL SPACES.
}

*R. s. wali ${ }^{1}$, nirani laxmi ${ }^{2}$ and basayya b. Mathad ${ }^{2}$.

1. Department of Mathematics, Bhandari \& Rathi College, Guledagudd-587 203, Karnataka, India.

2. Department of Mathematics, Rani Channamma University, Belagavi-591 156, Karnataka, India.

\section{Manuscript Info}

Manuscript History

Received: 23 June 2017

Final Accepted: 25 July 2017

Published: August 2017

Key words:-

RMG-closed maps, $\mathrm{RMG}^{*}$-closed maps,

RMG-open maps and RMG*-open

maps.

\section{Abstract}

In this article, we introduce a new class of RMG-closed and RMG-open maps in topological spaces and study some of their properties as well inter relationship with other closed and open maps.

\section{Introduction:-}

Different types of closed and open mappings were studied by various researchers in general topology. In 1982 Malghan [6] introduced and investigated some properties of generalized closed maps. El-Deeb et. al[3], M. Sheik John [15], N. Nagaveni[9], I Arockiarani[1] and Benchalli et. al[2] have introduced and studied pre-closed and preopen maps, w-closed and w-open maps, wg-closed, rwg-closed and wg-open, rwg-open maps, rg-closed and rg-open maps and rw-closed, rw-open maps respectively. But in this article we introduce new class of weaker forms of closed and open maps i.e. RMG-closed maps and RMG-open maps and also stronger form of RMG-closed and RMG-open maps called $\mathrm{RMG}^{*}$-closed and $\mathrm{RMG}^{*}$-open maps. Here we discuss the properties of all newly formed maps and relationship with existed maps in topological spaces.

\section{Preliminaries:-}

Throughout this paper $(\mathrm{X}, \tau),(\mathrm{Y}, \sigma)$ and $(\mathrm{Z}, \gamma)$ (or simply $\mathrm{X}, \mathrm{Y}$ and $\mathrm{Z}$ ) always means topological spaces on which no separation axioms are assumed unless explicitly stated. Let $\mathrm{A}$ be a subset of a space $\mathrm{X}$. We denote the closure, RMG-closure, interior, RMG-interior of A by cl(A), RMG-cl(A), int(A) and RMG-int(A) respectively and neighbourhood of an element in any topological space is denoted as nbd of $\mathrm{x} . \mathrm{X}-\mathrm{A}$ or $\mathrm{A}^{\mathrm{c}}$ denotes the complement of $\mathrm{A}$ in $\mathrm{X}$.

Now we recall the following known definitions and results that are used in our work;

Definition 2.1 A subset A of a topological space $X$ is called

(i) Regular open [16], if $A=\operatorname{int}(\mathrm{cl}(\mathrm{A}))$ and regular closed if $\mathrm{A}=\mathrm{cl}(\operatorname{int}(\mathrm{A}))$.

(ii) Pre-open [8], if $\mathrm{A} \subseteq \operatorname{int}(\mathrm{cl}(\mathrm{A}))$ and pre-closed if $\operatorname{cl}(\operatorname{int}(\mathrm{A})) \subseteq \mathrm{A}$.

(iii) $\alpha$-open [10], if $\mathrm{A} \subseteq \operatorname{int}(\operatorname{cl}(\operatorname{int}(\mathrm{A})))$ and $\alpha$-closed if $\operatorname{cl}(\operatorname{int}(\mathrm{cl}(\mathrm{A}))) \subseteq \mathrm{A}$.

Definition 2.2 A subset A of a topological space $\mathrm{X}$ is called 
(i) Generalized closed (briefly g-closed) [4] if $\operatorname{cl}(\mathrm{A}) \subseteq \mathrm{U}$ whenever $\mathrm{A} \subseteq \mathrm{U}$ and $\mathrm{U}$ is open in $\mathrm{X}$.

(ii) Generalized $\alpha$-closed (briefly g $\alpha$-closed) [7] if $\alpha$-cl(A) $\subseteq U$ whenever $A \subseteq U$ and $U$ is $\alpha$-open in $X$.

(iii) Weakly generalized closed (briefly wg-closed) [9] if cl(int(A)) $\subseteq \mathrm{U}$ whenever $\mathrm{A} \subseteq \mathrm{U}$ and $\mathrm{U}$ is open in $\mathrm{X}$.

(iv) Strongly generalized closed (briefly $\mathrm{g}^{*}$-closed) [15] if $\mathrm{cl}(\mathrm{A}) \subseteq \mathrm{U}$ whenever $\mathrm{A} \subseteq \mathrm{U}$ and $\mathrm{U}$ is g-open in $\mathrm{X}$.

(v) Weakly closed (briefly w-closed) [15] if $\operatorname{cl}(\mathrm{A}) \subseteq \mathrm{U}$ whenever $\mathrm{A} \subseteq \mathrm{U}$ and $\mathrm{U}$ is semi-open in $\mathrm{X}$.

(vi) Mildly generalized closed (briefly mildly g-closed) [12] if $\operatorname{cl}(\operatorname{int}(\mathrm{A})) \subseteq \mathrm{U}$ whenever $\mathrm{A} \subseteq \mathrm{U}$ and $\mathrm{U}$ is g-open in X.

(vii) Regular weakly generalized closed (briefly rwg-closed) [9] if $\operatorname{cl}(\operatorname{int}(\mathrm{A})) \subseteq \mathrm{U}$ whenever $\mathrm{A} \subseteq \mathrm{U}$ and $\mathrm{U}$ is regular open in X.

(viii) Regular weakly closed (briefly rw-closed)[2] if $\mathrm{cl}(\mathrm{A}) \subseteq \mathrm{U}$ whenever $\mathrm{A} \subseteq \mathrm{U}$ and $\mathrm{U}$ is regular semi open in $\mathrm{X}$.

(ix) Regular generalized closed (briefly rg-closed) [11] if $\operatorname{cl}(\mathrm{A}) \subseteq \mathrm{U}$ whenever $\mathrm{A} \subseteq \mathrm{U}$ and $\mathrm{U}$ is regular open set in $\mathrm{X}$.

The complements of above all closed sets are their respective open sets in the same topological space X.

Definition 2.3: A subset A of a space $X$ is said to be Regular Mildly Generalized closed (briefly RMG-closed) set [17], if $\operatorname{cl}(\operatorname{int}(\mathrm{A})) \subseteq \mathrm{U}$ whenever $\mathrm{A} \subseteq \mathrm{U}$ and $\mathrm{U}$ is rg-open set in $\mathrm{X}$.

Definition 2.4: A subset A of $X$ is called Regular Mildly Generalized open (briefly RMG-open) set [18], if X-A is RMG-closed set in X.

Definition 2.5: For a subset $A$ of a space $X, R M G-c l(A)=\Omega\{F: A \subseteq F$ and $F$ is RMG-closed set in $X\}$ is called RMGclosure of A [18].

Definition 2.6: Let $A$ is a subset of $X$. A point $x \in A$ is said to be RMG-interior point of $A$, if $A$ is a RMG-nhd of $x$. The set of all RMG-interior [18] of A and is denoted by RMG-int(A).

Definition 2.7: For a subset A of X, RMG-closure[18] of A is defined as RMG-cl(A) to be the intersection of all RMG-closed sets containing A.

Definition 2.8: Let $X$ be any topological space and let $x \in X$. A subset $N$ is said to be RMG-nbd[18] of $x$, if and only if there exists a RMG-open set $\mathrm{G}$ such that $\mathrm{x} \in \mathrm{G} \subseteq \mathbf{N}$.

Definition 2.9: $A$ subset $N$ of $X$ is a RMG-nbd[18] of $A \subseteq X$ in topological space $(X, \tau)$, if there exists a RMG-open set $\mathrm{G}$ such that $\mathrm{A} \subseteq \mathrm{X} \subseteq \mathbf{N}$.

Definition 2.10: A function $\mathrm{f}: \mathrm{X} \rightarrow \mathrm{Y}$ is said to be RMG-continuous function [19], if $\mathrm{f}^{-1}(\mathrm{~V})$ is RMG-closed set of $\mathrm{X}$ for every closed set $\mathrm{V}$ of $\mathrm{Y}$.

Definition 2.11 A function $\mathrm{f}: \mathrm{X} \rightarrow \mathrm{Y}$ is called RMG-irresolute [19], if $\mathrm{f}^{-1}(\mathrm{~V})$ is RMG-closed set in $\mathrm{X}$ for every RMG-closed subset $\mathrm{V}$ of $\mathrm{Y}$.

Definition 2.12A function $\mathrm{f}: \mathrm{X} \rightarrow \mathrm{Y}$ is said to be

(i) rg-irresolute [11], if $\mathrm{f}^{-1}(\mathrm{~V})$ is rg-open set in $\mathrm{X}$ for every rg-open set $\mathrm{V}$ of $\mathrm{Y}$.

(ii) strongly RMG-continuous [19], if $\mathrm{f}^{-1}(\mathrm{~V})$ is open set in $\mathrm{X}$ for every RMG-open set $\mathrm{V}$ of $\mathrm{Y}$.

Definition 2.13 A function $\mathrm{f}: \mathrm{X} \rightarrow \mathrm{Y}$ is called

(i) regular closed [5] if $\mathrm{f}(\mathrm{F})$ is closed in $\mathrm{Y}$ for every regular closed set $\mathrm{F}$ of $\mathrm{X}$.

(ii) g-closed [6] if $f(F)$ is g-closed in $Y$ for every closed set $F$ of $X$.

(iii) $\mathrm{w}$-closed [15] if $\mathrm{f}(\mathrm{F})$ is $\mathrm{W}$-closed in $\mathrm{Y}$ for every closed set $\mathrm{F}$ of $\mathrm{X}$.

(iv) pre-closed [3] if $f(F)$ is pre-closed in $Y$ for every closed set $F$ of $X$.

(v) $\mathrm{wg}^{*}\left(=\right.$ mildly-g)-closed [13] if $\mathrm{f}(\mathrm{F}) \mathrm{wg}^{*}$-closed in $\mathrm{Y}$ for every closed set $\mathrm{F}$ of $\mathrm{X}$.

(vi) wg-closed [9] if $\mathrm{f}(\mathrm{F})$ is wg-closed in $\mathrm{Y}$ for every closed set $\mathrm{F}$ of $\mathrm{X}$.

(vii) rwg-closed [9] if $\mathrm{f}(\mathrm{F})$ is rwg-closed in $\mathrm{Y}$ for every closed set $\mathrm{F}$ of $\mathrm{X}$.

(viii) rw-closed [2] if $f(F)$ is rw-closed in $Y$ for every closed set $F$ of $X$.

(ix) rg-closed [1] if $f(F)$ is rg-closed in $Y$ for every closed set $F$ of $X$.

$(x) g^{*}$-closed $[14]$ if $f(F)$ is $g^{*}$-closed in $Y$ for every closed set $F$ of $X$.

Definition 2.14: A function $\mathrm{f}: \mathrm{X} \rightarrow \mathrm{Y}$ is called

(i) regular open[5] if $f(F)$ is open in $Y$ for every regular open set $F$ of $X$.

(ii) g-open [6] if $f(F)$ is g-open in $Y$ for every open set $F$ of $X$.

(iii) w-open [15] if $f(F)$ is $w$-open in $Y$ for every open set $F$ of $X$.

(iv) pre-open [3] if $f(F)$ is pre-open in $Y$ for every open set $F$ of $X$.

(v) $\mathrm{wg}^{*}$-closed[13] if $f(F) \mathrm{wg}^{*}$-open in $Y$ for every open set $F$ of $X$.

(vi) wg-open [9] if $f(F)$ is wg-open in $Y$ for every open set $F$ of $X$.

(vii) rwg-open [9] if $f(F)$ is rwg-open in $Y$ for every open set $F$ of $X$.

(viii) rw-open [2] if $f(F)$ is rw-open in $Y$ for every open set $F$ of $X$. 
(ix) rg-open [1] if $\mathrm{f}(\mathrm{F})$ is rg-open in $\mathrm{Y}$ for every open set $\mathrm{F}$ of $\mathrm{X}$.

(x) $g^{*}$-open [14] if $f(F)$ is $g^{*}$-open in $Y$ for every open set $F$ of $X$.

Lemma 2.15: Let $X$ be any topological space, in which

(i) Every closed (resp. w-closed, g $\alpha$-closed, pre-closed) set is RMG-closed set in X [17].

(ii) Every RMG-closed set is mildly-g-closed (resp. wg-closed, rwg-closed) set in X [17].

Definition 2.16: A topological space $(X, \tau)$ is called

(i) $\mathrm{T}_{\mathrm{RMG}}$-space [19] if every RMG-closed set is closed.

(ii) $\mathrm{T}_{1 / 2}$-space [6] if every g-closed set is closed.

Definition 2.17: A function $\mathrm{f}: \mathrm{X} \rightarrow \mathrm{Y}$ is called

(i) closed if $\mathrm{f}(\mathrm{F})$ is closed in $\mathrm{Y}$ for every closed set $\mathrm{F}$ of $\mathrm{X}$.

(ii) $\mathrm{g} \alpha$-closed if $\mathrm{f}(\mathrm{F})$ is $\mathrm{g} \alpha$-close in $\mathrm{Y}$ for every closed set $\mathrm{F}$ of $\mathrm{X}$.

Definition 2.18: A function $\mathrm{f}: \mathrm{X} \rightarrow \mathrm{Y}$ is called

(i) open if $f(F)$ is open in $Y$ for every open set $F$ of $X$.

(ii) $\mathrm{g} \alpha$-open if $\mathrm{f}(\mathrm{F})$ is $\mathrm{g} \alpha$-open in $\mathrm{Y}$ for every open set $\mathrm{F}$ of $\mathrm{X}$.

Regula Mildly Generalized Closed Maps In Topological Spaces:-

Definition 3.1: A map f:X $\rightarrow \mathrm{Y}$ is said to be Regular Mildly Generalized closed (briefly, RMG-closed) map, if the image of every closed set in X is RMG-closed in Y.

Theorem 3.2: Every closed map is RMG-closed map but not conversely.

Proof: Let $\mathrm{f}: \mathrm{X} \rightarrow$ Yis closed map. Let $F$ be any closed set in $\mathrm{X}$. Then $\mathrm{f}(\mathrm{X})$ is closed but every closed set is RMGclosed set [17]. Hence $\mathrm{f}$ is RMG-closed map.

Example 3.3: Let $X=\{p, q, r\}$ with topology $\tau=\{X, \emptyset,\{p\},\{p, q\}\}$ and $Y=\{a, b, c, d\}$ with topology $\sigma=\{Y, \emptyset$, $\{\mathrm{a}\},\{\mathrm{b}, \mathrm{c}\},\{\mathrm{a}, \mathrm{b}, \mathrm{c}\}\}$. Let a map $\mathrm{f:}(\mathrm{X}, \tau) \rightarrow(\mathrm{Y}, \sigma)$ be defined as $\mathrm{f}(\mathrm{p})=\mathrm{c}, \mathrm{f}(\mathrm{q})=\mathrm{d}$ and $\mathrm{f}(\mathrm{r})=\mathrm{d}$. Then $\mathrm{f}$ is RMG-closed map but not closed, since the image of closed set $\{r\}$ in $X$ is $\{a\}$, which is not closed in $Y$.

Theorem 3.4: Every w-closed map is RMG-closed map but not conversely.

Proof: Let $\mathrm{f}: \mathrm{X} \rightarrow \mathrm{Y}$ is w-closed map. Let $\mathrm{F}$ be any closed set in $\mathrm{X}$. Then $\mathrm{f}(\mathrm{X})$ is w-closed but every w-closed set is RMG-closed set [17]. Hence $\mathrm{f}$ is RMG-closed map.

Example 3.5: Let $X=\{m, n, o\}$ with topology $\tau=\{X, \varnothing,\{m, n\}\}$ and $Y=\{a, b, c, d\}$ with topology $\sigma=\{Y, \emptyset,\{a\}$, $\{b, c\},\{a, b, c\}\}$. Let a map $f:(X, \tau) \rightarrow(Y, \sigma)$ be defined as $f(m)=a, f(n)=c$ and $f(o)=b$. Then $f$ is RMG-closed map but not w-closed, since the image of closed set $\{0\}$ in $\mathrm{X}$ is $\{b\}$, which is not $\mathrm{w}$-closed in $\mathrm{Y}$.

Theorem 3.6: Every g $\alpha$-closed map is RMG-closed map but not conversely.

Proof: Let $f: X \rightarrow Y$ is $g \alpha$-closed map. Let $F$ be any closed set in $X$. Then $f(X)$ is $g \alpha$-closed but every g $\alpha$-closed set is RMG-closed set [17]. Hence $f$ is RMG-closed map.

Example 3.7: Let $X=\{p, q\}$ with topology $\tau=\{X, \varnothing,\{p\}\}$ and $Y=\{a, b, c, d\}$ with topology $\sigma=\{Y, \varnothing,\{a\},\{b\},\{a$, b\} \}. Let a map f: $(X, \tau) \rightarrow(Y, \sigma)$ be defined as $f(p)=b$ and $f(q)=a$. Then $f$ is RMG-closed map but not $g \alpha$-closed, since the image of closed set $\{\mathrm{q}\}$ in $\mathrm{X}$ is $\{\mathrm{a}\}$, which is not $\mathrm{g} \alpha$-closed in $\mathrm{Y}$.

Theorem 3.8: Every pre-closed map is RMG-closed map but not conversely.

Proof: Let $f: X \rightarrow$ Yis pre-closed map. Let $F$ be any closed set in $X$. Then $f(X)$ is pre-closed but every pre-closed set is RMG-closed set [17]. Hence $f$ is RMG-closed map.

Example 3.9: Let $X=\{x, y, z\}$ with topology $\tau=\{X, \varnothing,\{x\},\{x, z\}\}$ and $Y=\{a, b, c, d\}$ with topology $\sigma=\{Y, \varnothing$, $\{\mathrm{a}\},\{\mathrm{b}\},\{\mathrm{a}, \mathrm{b}\},\{\mathrm{a}, \mathrm{b}, \mathrm{c}\}\}$. Let a map $\mathrm{f:}(\mathrm{X}, \tau) \rightarrow(\mathrm{Y}, \sigma)$ be defined as $\mathrm{f}(\mathrm{x})=\mathrm{p}, \mathrm{f}(\mathrm{y})=\mathrm{b}$, and $\mathrm{f}(\mathrm{z})=\mathrm{a}$. Then $\mathrm{f}$ is RMGclosed map but not pre-closed, since the image of closed set $\{y\}$ in $X$ is $\{b\}$, which is not pre-closed in $Y$.

Theorem 3.10: Every RMG-closed map is mildly- g-closed map but not conversely.

Proof: Let $\mathrm{f}: \mathrm{X} \rightarrow$ Yis RMG-closed map. Let $\mathrm{F}$ be any closed set in $\mathrm{X}$. Then $\mathrm{f}(\mathrm{X})$ is RMG-closed but every RMGclosed set is mildly-g-closed set[17]. Hence $\mathrm{f}$ is mildly-g-closed map.

Example 3.11: Let $X=\{a, b, c\}$ with topology $\tau=\{X, \emptyset,\{b, c\}\}$ and $Y=\{a, b, c, d\}$ with topology $\sigma=\{\varnothing,\{a\},\{b\}$, $\{a, b\},\{a, b, c\}, Y\}$. Let a map $f:(X, \tau) \rightarrow(Y, \sigma)$ be defined as $f(a)=a, f(b)=c$ and $f(c)=d$. Then $f$ is mildly-g-closed map but not RMG-closed, since the image of closed set $\{a\}$ in $X$ is $\{a\}$, which is not RMG-closed in $Y$.

Theorem 3.12: Every RMG-closed map is wg-closed map but not conversely.

Proof: Let $\mathrm{f}: \mathrm{X} \rightarrow$ Y is RMG-closed map. Let $\mathrm{F}$ be any closed set in $\mathrm{X}$. Then $\mathrm{f}(\mathrm{X})$ is RMG-closed but every RMGclosed set is wg-closed set[17]. Hence $\mathrm{f}$ is wg-closed map. 
Example 3.13: Let $X=\{p, q, r\}$ with topology $\tau=\{X, \emptyset,\{p\},\{q, r\}\}$ and $Y=\{a, b, c, d\}$ with topology $\sigma=\{Y, \emptyset$, $\{a\},\{b\},\{a, b\},\{a, b, c\}\}$. Let a map $f:(X, \tau) \rightarrow(Y, \sigma)$ be defined as $f(p)=b, f(q)=d$ and $f(r)=a$. Then $f$ is $w g-c l o s e d$ map but not RMG-closed, since the image of closed set $\{q, r\}$ in $X$ is $\{a, d\}$, which is not RMG-closed in $Y$.

Theorem 3.14: Every RMG-closed map is rwg-closed map but not conversely.

Proof: Let $\mathrm{f}: \mathrm{X} \rightarrow$ Y is RMG-closed map. Let $\mathrm{F}$ be any closed set in $\mathrm{X}$. Then $\mathrm{f}(\mathrm{X})$ is RMG-closed but every RMGclosed set is rwg-closed set[17]. Hence $\mathrm{f}$ is rwg-closed map.

Example 3.15: Let $X=\{x, y, z\}$ with topology $\tau=\{X, \emptyset,\{x\}\}$ and $Y=\{a, b, c, d\}$ with topology $\sigma=\{Y, \emptyset,\{a\},\{b\}$, $\{a, b\},\{b, c\},\{a, b, c\}\}$. Let a map $f:(X, \tau) \rightarrow(Y, \sigma)$ be defined as $f(x)=d, f(y)=a$ and $f(z)=b$. Then $f$ is rwg-closed map but not RMG-closed, since the image of closed set $\{y, z\}$ in $X$ is $\{a, b\}$, which is not RMG-closed in Y.

Remark 3.16: The regular closed map and RMG-closed maps are independent. This can be seen from following example.

Example 3.17: Let $\mathrm{X}=\{\mathrm{a}, \mathrm{b}, \mathrm{c}\}$ with topology $\tau=\{\mathrm{X}, \emptyset,\{\mathrm{a}, \mathrm{b}\}\}$ and $\mathrm{Y}=\{\mathrm{a}, \mathrm{b}, \mathrm{c}, \mathrm{d}\}$ with topology $\sigma=\{\mathrm{Y}, \emptyset,\{\mathrm{a}\}$, $\{b\},\{a, b\},\{a, b, c\}\}$. Let a map $f:(X, \tau) \rightarrow(Y, \sigma)$ be defined as $f(a)=c, f(b)=a$ and $f(c)=b$. Then $f$ is regular closed map but not RMG-closed, since the image of closed set $\{c\}$ in $X$ is $\{b\}$, which is not RMG-closed in Y.

Example 3.18: let $X=\{a, b, c\}$ with topology $\tau=\{X, \emptyset,\{a\},\{b\},\{a, b\}\}$ and $Y=\{a, b, c, d\}$ with topology $\sigma=\{Y$, $\emptyset,\{a\},\{b, c\},\{a, b, c\}\}$. Let a map $f:(X, \tau) \rightarrow(Y, \sigma)$ be a defined by $f(a)=a, f(b)=c$, and $f(c)=d$. Then $f$ is RMGclosed map but not regular closed map, since the image of regular closed set $\{a, c\}$ in $X$ is $\{b$, d \}, which is not closed set in $\mathrm{Y}$.

Remark 3.19: The following example show that g-closed maps and RMG-closed maps are independent.

Example 3.20: Let $X=\{p, q, r\}$ with topology $\tau=\{X, \emptyset,\{p, q\}\}$ and $Y=\{a, b, c, d\}$ with topology $\sigma=\{Y, \emptyset,\{a\}$, $\{b\},\{a, b\},\{a, b, c\}\}$. Let a map $f:(X, \tau) \rightarrow(Y, \sigma)$ be defined as $f(p)=d, f(q)=b$ and $f(r)=c$. Then $f$ is RMG-closed map but not g-closed, since the image of closed set $\{r\}$ in $X$ is $\{c\}$, which is not g-closed in $Y$.

Example 3.21: Let $X=\{p, q, r\}$ with topology $\tau=\{X, \varnothing,\{p\}\}$ and $Y=\{a, b, c, d\}$ with topology $\sigma=\{Y, \emptyset,\{a\},\{b\}$, $\{a, b\},\{a, b, c\}\}$. Let a map $f:(X, \tau) \rightarrow(Y, \sigma)$ be defined by $f(p)=c, f(q)=b$ and $f(r)=d$. Then $f$ is g-closed map but not RMG-closed, since the image of closed set $\{q, r\}$ in $X$ is $\{b, d\}$, which is not RMG-closed in $Y$.

Remark 3.22: The following example show that $\mathrm{g}^{*}$-closed maps and RMG-closed maps are independent.

Example 3.23: Let $X=\{p, q\}$ with topology $\tau=\{X, \emptyset,\{p\}\}$ and $Y=\{a, b, c, d\}$ with topology $\sigma=\{Y, \emptyset,\{a\},\{b\}$, $\{a, b\},\{a, b, c\}\}$. Let a map $f:(X, \tau) \rightarrow(Y, \sigma)$ be defined as $f(p)=b$, and $f(q)=c$. Then $f$ is RMG-closed map but not $\mathrm{g}^{*}$-closed, as the image of closed set $\{\mathrm{q}\}$ in $\mathrm{X}$ is $\{\mathrm{c}\}$, which is not $\mathrm{g}^{*}$-closed in $\mathrm{Y}$.

Example 3.24: Let $X=\{x, y, z\}$ with topology $\tau=\{X, \emptyset,\{x\}\}$ and $Y=\{a, b, c, d\}$ with topology $\sigma=\{Y, \emptyset,\{a\},\{b\}$, $\{a, b\},\{a, b, c\}\}$. Let a map $f:(X, \tau) \rightarrow(Y, \sigma)$ be defined as $f(x)=b, f(y)=a$ and $f(z)=d$. Then $f$ is $g^{*}-c l o s e d$ map but not RMG-closed, since the image of closed set $\{y, z\}$ in $X$ is $\{a, d\}$, which is not RMG-closed in $Y$.

Remark 3.25: The following example show that rw-closed maps and RMG-closed maps are independent.

Example 3.26: Let $X=\{a, b, c\}$ with topology $\tau=\{X, \emptyset,\{a\},\{a, c\}\}$ and $Y=\{a, b, c, d\}$ with topology $\sigma=\{Y, \emptyset$, $\{a\},\{b, c\},\{a, b, c\}\}$. Let a map $f:(X, \tau) \rightarrow(Y, \sigma)$ be defined by $f(a)=b, f(b)=c$ and $f(c)=d$. Then $f$ is RMG-closed map but not rw-closed, as the image of closed set $\{b\}$ in $X$ is $\{c\}$, which is not rw-closed in $Y$.

Example 3.27: Let $X=\{a, b, c\}$ with topology $\tau=\{X, \emptyset,\{a\},\{a, c\}\}$ and $Y=\{a, b, c, d\}$ with topology $\sigma=\{Y, \emptyset$, $\{a\},\{b\},\{a, b\},\{a, b, c\}\}$. Let a map $f:(X, \tau) \rightarrow(Y, \sigma)$ be defined by $f(a)=b, f(b)=c$ and $f(c)=a$. Then $f$ is rw-closed map but not RMG-closed, as the image of closed set $\{b\}$ in $X$ is $\{c\}$, which is not rw-closed in $Y$.

Remark 3.28: The following example show that rg-closed maps and RMG-closed maps are independent.

Example 3.29: Let $\mathrm{X}=\{\mathrm{x}, \mathrm{y}, \mathrm{z}\}$ with topology $\tau=\{\mathrm{X}, \emptyset,\{\mathrm{y}, \mathrm{z}\}\}$ and $\mathrm{Y}=\{\mathrm{a}, \mathrm{b}, \mathrm{c}, \mathrm{d}\}$ with topology $\sigma=\{\mathrm{Y}, \emptyset,\{\mathrm{a}\}$, $\{b\},\{a, b\},\{a, b, c\}\}$. Let a map $f:(X, \tau) \rightarrow(Y, \sigma)$ be defined by $f(x)=b, f(y)=a$ and $f(z)=d$. Then $f$ is $R M G-c l o s e d$ map but not rg-closed, as the image of closed set $\{x\}$ in $X$ is $\{b\}$, which is not rg-closed in $Y$.

Example 3.30: Let $X=\{x, y, z\}$ with topology $\tau=\{X, \emptyset,\{y\}\}$ and $Y=\{a, b, c, d\}$ with topology $\sigma=\{Y, \emptyset,\{a\},\{b$, $\mathrm{c}\},\{\mathrm{a}, \mathrm{b}, \mathrm{c}\}\}$. Let a map $\mathrm{f}:(\mathrm{X}, \tau) \rightarrow(\mathrm{Y}, \sigma)$ be defined by $\mathrm{f}(\mathrm{x})=\mathrm{b}, \mathrm{f}(\mathrm{y})=\mathrm{d}$ and $\mathrm{f}(\mathrm{z})=\mathrm{a}$. Then $\mathrm{f}$ is rg-closed map but not RMG-closed, as the image of closed set $\{x, z\}$ in $X$ is $\{a, b\}$, which is not RMG-closed in $Y$.

Remark 3.31: From the above discussion and known results we have the following implications. 
In the diagram, $A \longrightarrow B$ means $A$ implies $B$ but not conversely and
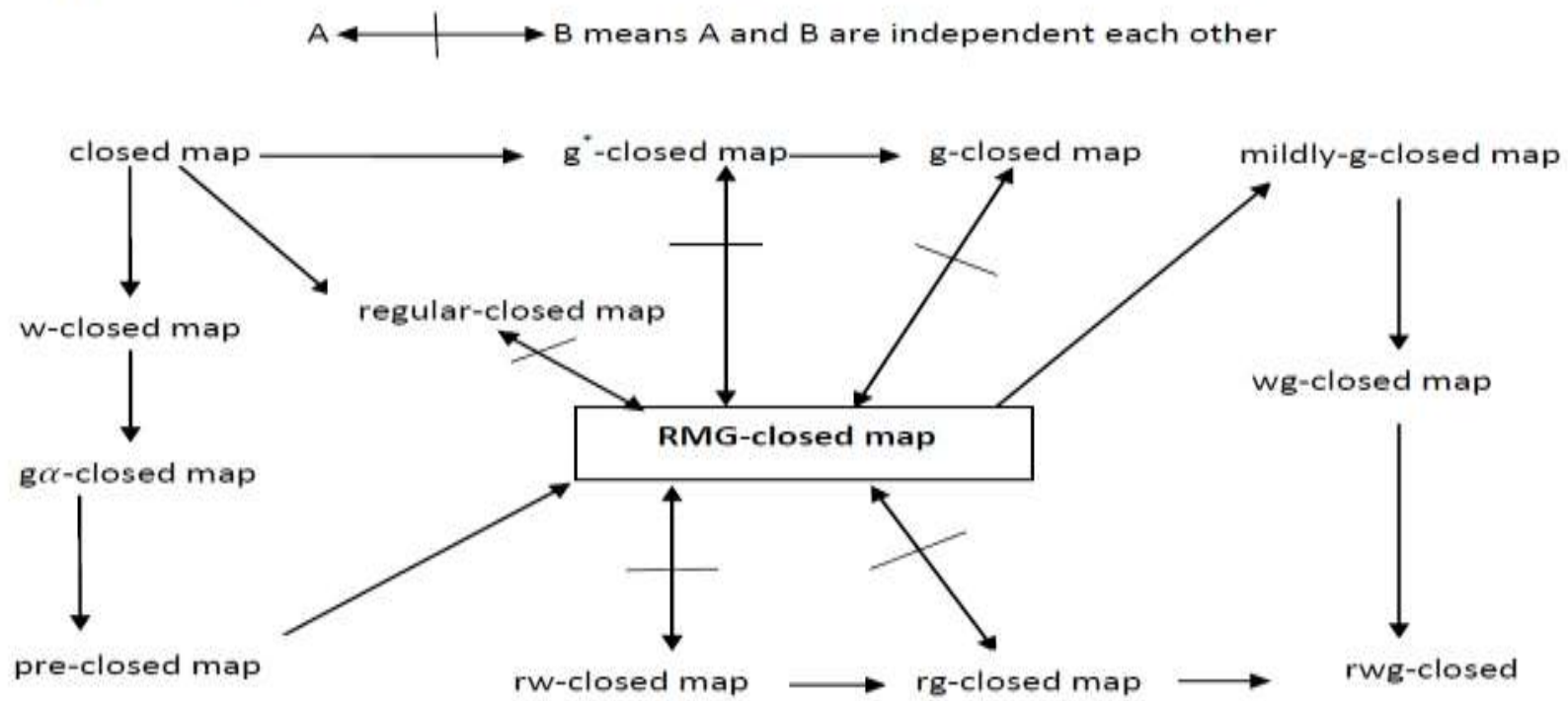

Remark 3.32: The composition of two RMG-closed maps need not be RMG-closed map in general. This can be shown by the following example.

Example 3.33: Let $X=\{p, q, r\}$ with topology $\tau=\{X, \emptyset,\{p\},\{p, r\}\}, Y=\{a, b, c, d\}$ with topology $\sigma=\{Y, \emptyset,\{a\}$, $\{b, c\},\{a, b, c\}\}$ and $Z=\{x, y, z, w\}$ with topology $\eta=\{Z, \varnothing,\{x\},\{y\},\{x, y\},\{y, z\},\{x, y, z\}\}$. Let a map f: $(X, \tau) \rightarrow(Y, \sigma)$ be defined as $\mathrm{f}(\mathrm{p})=\mathrm{c}, \mathrm{f}(\mathrm{q})=\mathrm{b}$ and $\mathrm{f}(\mathrm{r})=\mathrm{d}$ and $\mathrm{g}:(\mathrm{Y}, \sigma) \rightarrow(\mathrm{Z}, \eta)$ defined by $\mathrm{g}(\mathrm{a})=\mathrm{z}, \mathrm{g}(\mathrm{b})=\mathrm{x}, \mathrm{g}(\mathrm{c})=\mathrm{y}$ and $\mathrm{g}(\mathrm{d})=\mathrm{w}$. Then $\mathrm{f}$ and $\mathrm{g}$ are two RMG-closed maps but their composition $\mathrm{g} \circ \mathrm{f}:(\mathrm{X}, \tau) \rightarrow(\mathrm{Z}, \eta)$ is not RMG-closed map because $F=\{q\}$ is closed in $X$, but $(g \circ f)(F)=g(f(\{q\}))=g(\{b\})=\{x\}$, which is not RMG-closed in $Z$.

Theorem 3.34: If $\mathrm{f}: \mathrm{X} \rightarrow \mathrm{Y}$ is closed map and $\mathrm{g}: \mathrm{Y} \rightarrow \mathrm{Z}$ is $R M G$-closed map, then the $\mathrm{g} \circ \mathrm{f}: \mathrm{X} \rightarrow \mathrm{Z}$ is RMG-closed map. Proof: Let $F$ be any closed set in $X$. Since $f$ is closed map, $f(F)$ is closed set in $Y$. Since $g$ is RMG-closed map, $\mathrm{g}(\mathrm{f}(\mathrm{F}))=(\mathrm{g} \circ \mathrm{f})(\mathrm{F})$ is RMG-closed set in Z. Hence $\mathrm{g} \circ \mathrm{f}$ is RMG-closed map.

Remark 3.35: If $\mathrm{f}: \mathrm{X} \rightarrow \mathrm{Y}$ is $\mathrm{RMG}$-closed map and $\mathrm{g}: \mathrm{Y} \rightarrow \mathrm{Z}$ is closed map, then the composition need not be RMGclosed map. This can be seen from following example.

Example 3.36: Let $X=\{a, b, c\}$ with topology $\tau=\{X, \emptyset,\{a, b\}\}, Y=\{a, b, c, d\}$ with topology $\sigma=\{Y, \emptyset,\{a\},\{b$, $\mathrm{c}\},\{\mathrm{a}, \mathrm{b}, \mathrm{c}\}\}$ and $\mathrm{Z}=\{\mathrm{a}, \mathrm{b}, \mathrm{c}, \mathrm{d}\}$ with topology $\eta=\{\mathrm{Z}, \emptyset,\{\mathrm{a}\},\{\mathrm{b}\},\{\mathrm{a}, \mathrm{b}\},\{\mathrm{a}, \mathrm{b}, \mathrm{c}\}\}$. Let a map f: $(\mathrm{X}, \tau) \rightarrow(\mathrm{Y}, \sigma)$ be defined as $f(a)=c, f(b)=d$ and $f(c)=b$ and $g:(Y, \sigma) \rightarrow(Z, \eta)$ defined by $g(a)=c, g(b)=b, g(c)=c$ and $g(d)=d$. Then $f$ is RMG-closed map and $g$ is a closed map but their composition $g \circ f:(X, \tau) \rightarrow(Z, \eta)$ is not RMG-closed map because $F=\{c\}$ is closed in $X$, but $(g \circ f)(F)=g(f(\{c\}))=g(\{b\})=\{b\}$, which is not RMG-closed in $Z$.

Theorem 3.37: If $f: X \rightarrow Y$ and $g: Y \rightarrow Z$ are two $R M G-c l o s e d$ maps and $Y$ be a $T_{R M G}$-space then gof: $X \rightarrow Z$ is $R M G-$ closed map.

Proof: Let $A$ be a closed set of $X$. Since $f$ is $R M G$-closed map, $f(A)$ is RMG-closed in $Y$. Then by hypothesis, $f(A)$

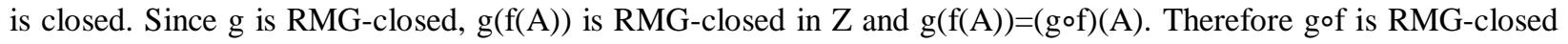
map.

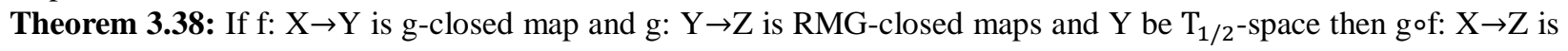
RMG-closed map.

Proof: Let $A$ be a closed set of $X$. Since $f$ is $g$-closed, $f(A)$ is g-closed in Y. Since $Y$ is $T_{1 / 2}, f(A)$ is closed in $Y$. Since $g$ is RMG-closed, $g(f(A))$ is $R M G$-closed in $Z$ and $g(f(A))=(g \circ f)(A)$. Therefore $g \circ f$ is RMG-closed map.

Theorem 3.39: Composition of closed maps is RMG-closed map.

Proof: Proof is straight forward and fact that every closed set is RMG-closed set.

Theorem 3.40: A map $f: X \rightarrow Y$ is said to be RMG-closed map if and only if for each subset $A$ of $Y$ and for each open set $U$ containing $f^{-1}(A)$, there is a RMG-open set $V$ of $Y$ such that $A \subseteq V$ and $f^{-1}(V) \subseteq U$.

Proof: Suppose $\mathrm{f}$ is RMG-closed map. Let $\mathrm{A}$ is a subset of $\mathrm{Y}$ and $\mathrm{U}$ is a open set of $\mathrm{X}$ such that $\mathrm{f}^{-1}(\mathrm{~A}) \subseteq \mathrm{U}$. Now $\mathrm{X}-$ $U$ is a closed set in $X$. Since $f$ is $R M G$-closed map, $f(X-U)$ is a RMG-closed set in $Y$ i.e. $V=Y-f(X-U), V=Y-f(X-U)$ is $R M G-o p e n$ set of $Y$. Note that $f^{-1}(A) \subseteq U$ implies that $A \subseteq V$ and $f^{-1}(V)=X-f^{-1}(f(X-U))=X-(X-U)=U$ i.e.f ${ }^{-1}(\mathrm{~V}) \subseteq \mathrm{U}$. 
Conversely, suppose that $F$ is a closed set in $X$. Then $f^{-1}(f(X-F)) \subseteq X-F$ and $X-F$ is open in $X$. By the hypothesis, there exists a RMG-open set $\mathrm{V}$ in $\mathrm{Y}$ such that $\mathrm{Y}-\mathrm{f}(\mathrm{F}) \subseteq \mathrm{V}$ andf $\mathrm{f}^{-1}(\mathrm{~V}) \subseteq \mathrm{X}-\mathrm{F}$. Therefore, $\mathrm{F} \subseteq \mathrm{X}-\mathrm{f}^{-1}(\mathrm{~V})$. Hence $\mathrm{Y}$ $V \subseteq f(F) \subseteq f\left(X-f^{-1}(V)\right) \subseteq Y-V$ which implies $f(F) \subseteq V$. Since $Y-V$ is RMG-closed, $f(F)$ is RMG-closed. Therefore $f(F)$ is RMG-closed in Y. Hence $\mathrm{f}$ is RMG-closed map.

Theorem 3.41: If $\mathrm{f}: \mathrm{X} \rightarrow \mathrm{Y}$ is g-closed map and $\mathrm{Y}$ is a $T_{1 / 2}$-space, then $\mathrm{f}: \mathrm{X} \rightarrow \mathrm{Y}$ is RMG-closed map.

Proof: Let $F$ be a closed set in X. Since $f$ is g-closed map, $f(F)$ is g-closed set in $Y$. As $Y$ is a $T_{1 / 2}$-space, we have $\mathrm{f}(\mathrm{F})$ is closed in $\mathrm{Y}$. As every closed set is RMG-closed, $\mathrm{f}(\mathrm{F})$ is a RMG-closed in $\mathrm{Y}$. Thus $\mathrm{f}$ is a RMG-closed map.

Theorem 3.42: If $f: X \rightarrow Y$ is RMG-closed map, then RMG-cl(f(A)) $\subseteq f(c l(A))$ for every subset $A$ of $X$.

Proof: Suppose that $f$ is RMG-closed and $A \subseteq X$. Then cl(A) is closed in $X$ and so $f(\operatorname{cl}(A))$ is RMG-closed in $Y$. We

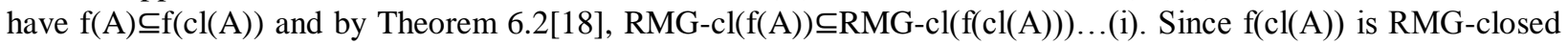

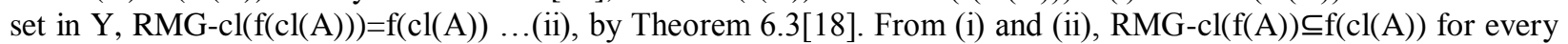
subset A of X.

Corollary 3.43: If $\mathrm{f}: \mathrm{X} \rightarrow \mathrm{Y}$ is a RMG-closed then the image $\mathrm{f}(\mathrm{A})$ of closed set $\mathrm{A}$ in $\mathrm{X}$ is $\tau_{\mathrm{RMG}}$-closed in $\mathrm{Y}$.

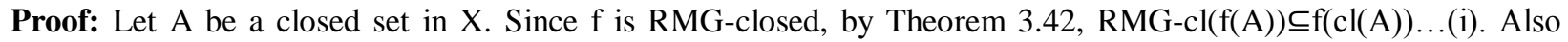
$\operatorname{cl}(A)=A$ as $A$ is a closed set and so $f(\operatorname{cl}(A))=f(A) \ldots$ (ii). From (i) and (ii), $R M G-c l(f(A)) \subseteq f(A)$. We know that $\mathrm{f}(\mathrm{A}) \subseteq \mathrm{RMG}-\mathrm{cl}(\mathrm{A})$ and so RMG-cl( $(\mathrm{f}(\mathrm{A}))=\mathrm{f}(\mathrm{A})$. Therefore $\mathrm{f}(\mathrm{A})$ is $\tau_{\mathrm{RMG}}$-closed in $\mathrm{Y}$.

Theorem 3.44: Let $X$ and $Y$ are two topological spaces where ' $R M G-c l(A)=p c l(A)$ for every subset $A$ of $Y$ ' and $\mathrm{f}: \mathrm{X} \rightarrow \mathrm{Y}$ be map, then the following are equivalent;

(i) $\mathrm{f}$ is RMG-closed map.

(ii) $\mathrm{RMG}-\mathrm{cl}(\mathrm{f}(\mathrm{A})) \subseteq \mathrm{f}(\mathrm{cl}(\mathrm{A}))$ for every subset $\mathrm{A}$ of $\mathrm{X}$.

Proof: (i) $\Rightarrow$ (ii) follows from the Theorem 3.42 .

(ii) $\Rightarrow$ (i), let $A$ be any closed set of $X$ then $A=\operatorname{cl}(A)$ and so $R M G-c l(f(A)) \subseteq f(\operatorname{cl}(A))=f(A)$, by hypothesis. We have $\mathrm{f}(\mathrm{A}) \subseteq R M G-\mathrm{cl}(\mathrm{A})$ by Theorem 6.2[18]. Therefore $\mathrm{f}(\mathrm{A})=\mathrm{RMG}-\mathrm{cl}(\mathrm{f}(\mathrm{A}))$. Also $\mathrm{f}(\mathrm{A})=\mathrm{RMG}-\mathrm{cl}(\mathrm{f}(\mathrm{A}))=\mathrm{pcl}(\mathrm{f}(\mathrm{A}))$, by hypothesis. i.e. $f(A)=\operatorname{pcl}(f(A))$ and so $f(A)$ is pre-closed set in $Y$. Thus $f(A)$ is RMG-closed set in $Y$. Hence $f$ is RMG-closed map.

Theorem 3.45: Let $f_{i}:\left(X_{i}, \tau_{i}\right) \rightarrow\left(X_{i+1}, \tau_{i+1}\right)$ be a map, then following are true;

(i) If $f_{1}, f_{2}, f_{3}, \ldots, f_{n}$ are closed maps then their compositions $f_{n} \circ f_{n-1} \circ f_{n-2} \circ \ldots \circ f_{1}$ is RMG-closed map.

(ii) If $f_{1}, f_{2}, f_{3}, \ldots, f_{n-1}$ are closed maps and $f_{n}$ is a RMG-closed map then the compositions $f_{n} \circ f_{n-1} \circ f_{n-2} \circ \ldots \circ$ $f_{1}$ is RMG-closed map.

Proof: (i) The proof follows from the Theorem 3.39 and fact that every closed set is RMG-closed set.

(ii) The proof follows from the Theorem 3.34.

Theorem 3.46: If $\mathrm{f}: \mathrm{X} \rightarrow \mathrm{Y}$ and $\mathrm{g}: \mathrm{Y} \rightarrow \mathrm{Z}$ are two mappings such that their composition $\mathrm{g} \circ \mathrm{f}: \mathrm{X} \rightarrow \mathrm{Z}$ is $\mathrm{RMG}$-closed map, then the following statements are true;

(i) If $\mathrm{f}$ is continuous and surjective, then $\mathrm{g}$ is RMG-closed map.

(ii) If $\mathrm{g}$ is RMG-irresolute and injective, then $\mathrm{f}$ is RMG-closed map.

(iii) If $\mathrm{f}$ is $\mathrm{g}$-continuous, surjective and $\mathrm{X}$ is a $\mathrm{T}_{1 / 2}$-space, then $\mathrm{g}$ is RMG-closed map.

(iv) If $\mathrm{g}$ is strongly RMG-continuous and injective, then $\mathrm{f}$ is RMG-closed map.

Proof: (i) Let $A$ be a closed set of $X$. Since $f$ is continuous, $f^{-1}(A)$ is closed in $X$ and since gof is RMG-closed, $(\mathrm{g} \circ \mathrm{f})\left(\mathrm{f}^{-1}(\mathrm{~A})\right)$ is $\mathrm{RMG}$-closed in Z. i.e. $\mathrm{g}(\mathrm{A})$ is RMG-closed in $\mathrm{Z}$, since $\mathrm{f}$ is surjective. Therefore $\mathrm{g}$ is RMG-closed map.

(ii) Let B be a closed set of X. Since $\mathrm{g} \circ \mathrm{f}$ is RMG-closed, ( $\circ \circ \mathrm{f})(\mathrm{B})$ is RMG-closed in Z. Since $\mathrm{g}$ is RMG-irresolute, $\mathrm{g}^{-1}((\mathrm{~g} \circ \mathrm{f})(\mathrm{B}))$ is RMG-closed set in $\mathrm{Y}$ implies that $\mathrm{f}(\mathrm{B})$ is RMG-closed in $\mathrm{Y}$, since $\mathrm{f}$ is injective. Therefore $\mathrm{f}$ is RMG-closed map.

(iii) Let $\mathrm{C}$ be a closed set of $\mathrm{Y}$. Since $\mathrm{f}$ is g-continuous, $\mathrm{f}^{-1}(\mathrm{C})$ is $\mathrm{g}$-closed set in $\mathrm{X}$. Since $\mathrm{X}$ is a $\mathrm{T}_{1 / 2}$-space, $\mathrm{f}^{-1}(\mathrm{C})$ is RMG-closed set in X. Since $\mathrm{g} \circ \mathrm{f}$ is RMG-closed, $(\mathrm{g} \circ \mathrm{f})\left(\mathrm{f}^{-1}(\mathrm{C})\right.$ ) is RMG-closed in Z implies $\mathrm{g}(\mathrm{C})$ is RMG-closed in $\mathrm{Z}$, since $\mathrm{f}$ is surjective. Therefore $\mathrm{g}$ is RMG-closed map.

(iv) Let $\mathrm{D}$ be a closed set of $\mathrm{X}$. Since ( $\mathrm{g} \circ \mathrm{f})(\mathrm{D})$ is RMG-closed in Z. Since $\mathrm{g}$ is strongly RMG-continuous, $\mathrm{g}^{-1}((\mathrm{~g} \circ \mathrm{f})(\mathrm{D}))$ is closed set in $\mathrm{Y}$ implies $\mathrm{f}(\mathrm{D})$ is closed set in $\mathrm{Y}$, since $\mathrm{g}$ is injective. Therefore $\mathrm{f}$ is closed map.

Theorem 3.47: If $\mathrm{f}: \mathrm{X} \rightarrow \mathrm{Y}$ is rg-irresolute, RMG-closed and $\mathrm{A}$ is a RMG-closed subset of $\mathrm{X}$, then $\mathrm{f}(\mathrm{A})$ is a RMGclosed set in $\mathrm{Y}$.

Proof: Let $f(A) \subseteq G$, where $G$ is a rg open in $Y$. Since $f$ is rg-irresolute, $f^{-1}(G)$ is rg-open in $X$ by definition 2.12 and $A \subseteq f^{-1}(G)$. Since $A$ is a $R M G$-closed set in $X, \operatorname{cl}(\operatorname{int}(A)) \subseteq f^{-1}(G)[19]$. Since $f$ is RMG-closed, $f(\operatorname{cl}(\operatorname{int}(A)))$ is RMG-closed set contained in $\operatorname{rg}$-open set $\mathrm{G}$ implies that $\operatorname{cl}(\operatorname{int}(\mathrm{f}(\operatorname{cl}(\operatorname{int}(\mathrm{A}))))) \subseteq f(\operatorname{cl}(\operatorname{int}(\mathrm{A})) \subseteq G$ and so $\operatorname{cl}(\operatorname{int}(\mathrm{f}(\mathrm{A}))) \subseteq \mathrm{G}$. Hence $\mathrm{f}(\mathrm{A})$ is RMG-closed set in $\mathrm{Y}$. 
Corollary 3.48: If $\mathrm{f}: \mathrm{X} \rightarrow \mathrm{Y}$ be a RMG-closed map and $\mathrm{g}$ : $\mathrm{Y} \rightarrow \mathrm{Z}$ be RMG-closed and rg-irresolute map, then their composition $\mathrm{g} \circ \mathrm{f}: \mathrm{X} \rightarrow \mathrm{Z}$ is $\mathrm{RMG}$-closed map.

Proof: Let A be a closed set of X. Since $f$ is a RMG-closed map, $f(A)$ is RMG-closed in Y. Since $g$ is both RMGclosed and rg-irresolute, $g(f(A))$ is RMG-closed in $Z$ by Theorem 3.47. Also $g(f(A))=(g \circ f)(A)$. Therefore $g \circ f$ is RMG-closed map.

Theorem 3.49: If $\mathrm{f}: \mathrm{X} \rightarrow \mathrm{Y}$ is an open, continuous, $\mathrm{RMG}$-closed, surjection and $\mathrm{cl}(\operatorname{int}(\mathrm{F}))=\mathrm{F}$ for every RMG-closed set in $\mathrm{Y}$, where $\mathrm{X}$ is regular, then $\mathrm{Y}$ is regular.

Proof: Let $U$ be an open set in $Y$ and $p \in U$. Since $f$ is surjection, there exists a point $x \in X$ such that $f(x)=p$. Since $X$ is regular and $\mathrm{f}$ is continuous, there is an open set $\mathrm{V}$ in $\mathrm{X}$ such that $\mathrm{x} \in \mathrm{V} \subseteq \operatorname{cl}(\operatorname{int}(\mathrm{V})) \subseteq \mathrm{f}^{-1}(\mathrm{U})$. Here $\mathrm{p} \in \mathrm{f}(\mathrm{V}) \subseteq \mathrm{f}(\mathrm{cl}(\mathrm{int}(\mathrm{V}))) \subseteq \mathrm{U}$...(i). Since $\mathrm{f}$ is RMG-closed, $\mathrm{f}(\mathrm{cl}(\mathrm{int}(\mathrm{V})))$ is a RMG-closed set contained in the open set $\mathrm{U}$. By hypothesis $\operatorname{cl}(\operatorname{int}(\mathrm{f}(\operatorname{cl}(\operatorname{int}(\mathrm{A})))))=\mathrm{f}(\mathrm{cl}(\operatorname{int}(\mathrm{V})))$ and $\operatorname{cl}(\operatorname{int}(\mathrm{f}(\mathrm{V}))) \subseteq \operatorname{cl}(\operatorname{int}(\mathrm{f}(\mathrm{cl}(\operatorname{int}(\mathrm{V})))))$...(ii). From (i) and (ii), $p \in f(V) \subseteq f(\operatorname{cl}(\operatorname{int}(V))) \subseteq U$ and $f(V)$ is open, since $f$ is open. Hence $Y$ is regular.

Theorem 3.50: If $f: X \rightarrow Y$ is $R M G$-closed and $A$ is closed set of $X$, then its restriction $f_{A}:\left(A, \tau_{A}\right) \rightarrow Y$ is RMG-closed map.

Proof: Let $F$ be a closed set of $A$. Then $F=A \cap E$ for some closed set $E$ of $X$ and so $F$ is closed set of $X$. Since $f$ is RMG-closed, $f(F)$ is RMG-closed set in $Y$. But $f(F)=f_{A}(F)$. Therefore $f_{A}:\left(A, \tau_{A}\right) \rightarrow Y$ is RMG-closed map.

Now we define the new class of stronger form of RMG-closed maps is called RMG*-closed maps in topological spaces.

Definition 3.51: A map f: $\mathrm{X} \rightarrow \mathrm{Y}$ is said to be RMG*-closed maps, if the image of every RMG-closed set of $\mathrm{X}$ is RMG-closed set in Y.

Theorem 3.52: If $\mathrm{f}: \mathrm{X} \rightarrow \mathrm{Y}$ is $\mathrm{RMG}^{*}$-closed map, then which is RMG-closed map, but not conversely.

Proof: Let $\mathrm{F}$ be a closed set in $\mathrm{X}$ and the fact that every closed set is RMG-closed set. Hence F is RMG-closed set in $X$. Since $f: X \rightarrow Y$ be a RMG*-closed map, $f(F)$ is RMG-closed set in $Y$. Therefore $f$ is RMG-closed map.

Example 3.53: Let $X=\{a, b, c, d\}$ with topology $\tau=\{X, \varnothing,\{a\},\{b, c\},\{a, b, c\}\}$ and $Y=\{a, b, c, d\}$ with topology $\sigma=\{\mathrm{Y}, \emptyset,\{\mathrm{a}\},\{\mathrm{b}\},\{\mathrm{a}, \mathrm{b}\},\{\mathrm{a}, \mathrm{b}, \mathrm{c}\}\}$. Let a map f: $(\mathrm{X}, \tau) \rightarrow(\mathrm{Y}, \sigma)$ be defined as $\mathrm{f}(\mathrm{a})=\mathrm{c}, \mathrm{f}(\mathrm{b})=\mathrm{a}, \mathrm{f}(\mathrm{c})=\mathrm{d}$ and $\mathrm{f}(\mathrm{d})=\mathrm{b}$. Then $f$ is RMG-closed map but not RMG*-closed, since the image of RMG-closed set $\{b, d\}$ in $X$ is $\{a, b\}$, which is not RMG-closed in Y.

Theorem 3.54: If $\mathrm{f}: \mathrm{X} \rightarrow \mathrm{Y}$ and $\mathrm{g}: \mathrm{Y} \rightarrow \mathrm{Z}$ are two $\mathrm{RMG}^{*}$-closed maps, then their composition $\mathrm{g}$ of: $\mathrm{X} \rightarrow \mathrm{Z}$ is $\mathrm{RMG}^{*}$ closed map.

Proof: Let $F$ be a RMG-closed set in X. Since $f$ is $R M G^{*}$-closed map, $f(F)$ is RMG-closed set in $Y$. Since $g$ is $\mathrm{RMG}^{*}$-closed map, $\mathrm{g}(\mathrm{f}(\mathrm{F}))$ is RMG-closed set in $\mathrm{Z}$. Hence $\mathrm{g}$ of is $\mathrm{RMG}^{*}$-closed map.

Theorem 3.56: If $\mathrm{f}: \mathrm{X} \rightarrow \mathrm{Y}$ is irresolute and RMG-closed map then $\mathrm{f}$ is $\mathrm{RMG}^{*}$-closed map.

Theorem 3.57: If $f: X \rightarrow Y$ be a closed map and $g: Y \rightarrow Z$ be $R M G^{*}$-closed, then their composition $g \circ f: X \rightarrow Z$ is RMG-closed map.

Proof: Let $\mathrm{F}$ be a closed set in $\mathrm{X}$. Then $\mathrm{f}(\mathrm{F})$ is closed in $\mathrm{Y}$. The fact that every closed set is RMG-closed set implies that $f(F)$ is RMG-closed set in Y. Since $g$ is $R M G^{*}$-closed map, $g(f(F))=(g \circ f)(F)$ is RMG-closed set in Z. Hence gof is RMG-closed map.

Theorem 3.58: If $\mathrm{f}: \mathrm{X} \rightarrow \mathrm{Y}$ be a RMG-closed map and $\mathrm{g}: \mathrm{Y} \rightarrow \mathrm{Z}$ be $\mathrm{RMG}{ }^{*}$-closed, then their composition $\mathrm{g} \circ \mathrm{f}: \mathrm{X} \rightarrow \mathrm{Z}$ is RMG-closed map.

Proof: Let $\mathrm{F}$ be a closed set in $\mathrm{X}$. Since $\mathrm{f}$ is RMG-closed map, $\mathrm{f}(\mathrm{F})$ is RMG-closed set in Y. Since $\mathrm{g}$ is RMG*closed map, $g(f(F))=(g \circ f)(F)$ is RMG-closed set in Z. Hence $g \circ f$ is RMG-closed map.

Regular Mildly Generalized Open Maps In Topological Spaces:-

Definition 4.1: A map f: $X \rightarrow Y$ is said to be Regular Mildly Generalized open (briefly, RMG-open) map, if the image of every open set in $\mathrm{X}$ is RMG-open in Y.

From the definition 4.1 we have following results;

Theorem 4.2: (i) Every open map is RMG-open map, but not conversely.

(ii) Every w-open map is RMG-open map, but not conversely.

(iii) Every g $\alpha$-open map is RMG-open map, but not conversely.

(iv) Every pre-open map is RMG-open map, but not conversely.

(v) Every RMG-open map is mildly-g-open map, but not conversely

(vi) Every RMG-open map is wg-open map, but not conversely.

(vii) Every RMG-open map is rwg-open map, but not conversely.

Proof: Proofs follow from Definition 4.1 and fact that lemma 2.14. 
Example 4.3: Let $X=\{s, t, r\}$ with topology $\tau=\{X, \varnothing,\{s\},\{s, r\}\}$ and $Y=\{a, b, c, d\}$ with topology $\sigma=\{Y, \emptyset,\{a\}$, $\{\mathrm{b}, \mathrm{c}\},\{\mathrm{a}, \mathrm{b}, \mathrm{c}\}\}$. Let a map $\mathrm{f}:(\mathrm{X}, \tau) \rightarrow(\mathrm{Y}, \sigma)$ be defined as $\mathrm{f}(\mathrm{s})=\mathrm{b}, \mathrm{f}(\mathrm{t})=\mathrm{c}$ and $\mathrm{f}(\mathrm{r})=\mathrm{a}$. Then $\mathrm{f}$ is RMG-open map but not open, since the image of open set $\{s\}$ in $X$ is $\{b\}$, which is not open in $Y$.

Example 4.4: Let $X=\{p, q$,$\} with topology \tau=\{X \varnothing,\{p\}\}$ and $Y=\{a, b, c, d\}$ with topology $\sigma=\{Y, \emptyset,\{a\},\{b\}$, $\{\mathrm{a}, \mathrm{b}\},\{\mathrm{b}, \mathrm{c}\},\{\mathrm{a}, \mathrm{b}, \mathrm{c}\}\}$. Let a map $\mathrm{f:}(\mathrm{X}, \tau) \rightarrow(\mathrm{Y}, \sigma)$ be defined as $\mathrm{f}(\mathrm{p})=\mathrm{c}$, and $\mathrm{f}(\mathrm{q})=\mathrm{a}$. Then $\mathrm{f}$ is RMG-open map but not w-open, since the image of open set $\{p\}$ in $X$ is $\{c\}$, which is not w-open in $Y$.

Example 4.5:Let $\mathrm{X}=\{\mathrm{x}, \mathrm{y}, \mathrm{z}\}$ with topology $\tau=\{\mathrm{X}, \emptyset,\{\mathrm{z}\},\{\mathrm{x}, \mathrm{z}\}\}$ and $\mathrm{Y}=\{\mathrm{a}, \mathrm{b}, \mathrm{c}, \mathrm{d}\}$ with topology $\sigma=\{\mathrm{Y}, \emptyset,\{\mathrm{a}\}$, $\{b\},\{a, b\},\{b, c\},\{a, b, c\}\}$. Let a map $f:(X, \tau) \rightarrow(Y, \sigma)$ be defined as $f(x)=b, f(y)=d$ and $f(z)=c$. Then $f$ is RMGopen map but not $\mathrm{g} \alpha$-open, since the image of open set $\{\mathrm{z}\}$ in $\mathrm{X}$ is $\{\mathrm{c}\}$, which is not $\mathrm{g} \alpha$-open in $\mathrm{Y}$.

Example 4.6: Let $X=\{m, n, o\}$ with topology $\tau=\{X, \emptyset,\{m, n\}\}$ and $Y=\{a, b, c, d\}$ with topology $\sigma=\{Y, \emptyset,\{a\}$, $\{\mathrm{b}, \mathrm{c}\},\{\mathrm{a}, \mathrm{b}, \mathrm{c}\}\}$. Let a map $\mathrm{f:}(\mathrm{X}, \tau) \rightarrow(\mathrm{Y}, \sigma)$ be defined as $\mathrm{f}(\mathrm{m})=\mathrm{a}, \mathrm{f}(\mathrm{n})=\mathrm{c}$ and $\mathrm{f}(\mathrm{o})=\mathrm{b}$. Then $\mathrm{f}$ is RMG-open map but not pre-open, since the image of open set $\{\mathrm{m}, \mathrm{n}\}$ in $\mathrm{X}$ is $\{\mathrm{a}, \mathrm{c}\}$, which is not pre-open in $\mathrm{Y}$.

Example 4.7: Let $X=\{p, q, r\}$ with topology $\tau=\{X, \varnothing,\{p\},\{q\},\{p, q\}\}$ and $Y=\{a, b, c, d\}$ with topology $\sigma=\{Y$, $\emptyset,\{a\},\{b\},\{a, b\},\{a, b, c\}\}$. Let a map $f:(X, \tau) \rightarrow(Y, \sigma)$ be defined as $f(p)=b, f(q)=c$ and $f(r)=a$. Then $f$ is mildlyg-open map but not RMG-open, since the image of open set $\{p, q\}$ in $X$ is $\{b, c\}$, which is not RMG-open in $Y$.

Example 4.8: Let $X=\{x, y, z\}$ with topology $\tau=\{X, \varnothing,\{x, y\}\}$ and $Y=\{a, b, c, d\}$ with topology $\sigma=\{Y, \varnothing,\{a\}$, $\{b\},\{a, b\},\{b, c\},\{a, b, c\}\}$. Let a map $f:(X, \tau) \rightarrow(Y, \sigma)$ be defined as $f(x)=a, f(y)=c$ and $f(z)=b$. Then $f$ is $w g-$ open map but not RMG-open, since the image of open set $\{x, y\}$ in $X$ is $\{a, c\}$, which is not RMG-open in $Y$.

Example 4.9: Let $X=\{m, n, o\}$ with topology $\tau=\{X, \varnothing,\{m\}\}$ and $Y=\{a, b, c, d\}$ with topology $\sigma=\{Y, \emptyset,\{a\},\{b$, $c\},\{a, b, c\}\}$. Let a map $f:(X, \tau) \rightarrow(Y, \sigma)$ be defined as $f(m)=d, f(n)=a$ and $f(o)=b$. Then $f$ is rwg-open map but not RMG-open, since the image of open set $\{\mathrm{m}\}$ in $X$ is $\{d\}$, which is not RMG-open in $Y$

Theorem 4.10: If $f: X \rightarrow Y$ is $R M G-o p e n$, then $f(\operatorname{int}(A)) \subseteq R M G-i n t(f(A))$ for every subset $A$ of $X$.

Proof: Let $f: X \rightarrow Y$ is an open map and $A$ is any subset of $X$. Then $\operatorname{int}(A)$ is open in $X$ and so $f(\operatorname{int}(A))$ is RMG-open

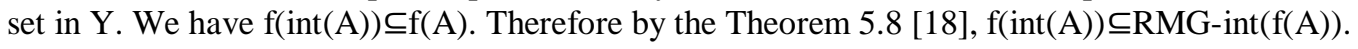

Theorem 4.11: A map $\mathrm{f}: \mathrm{X} \rightarrow \mathrm{Y}$ be RMG-open if and only if for any subset $\mathrm{S}$ of $\mathrm{Y}$ and any closed set of $\mathrm{X}$ containing $\mathrm{f}^{-1}(\mathrm{~S})$, there exists a RMG-closed set $\mathrm{T}$ of $\mathrm{Y}$ containing $\mathrm{S}$ such that $\mathrm{f}^{-1}(\mathrm{~T}) \subseteq F$.

Proof: Suppose $f: X \rightarrow Y$ is RMG-open map. Let $S \subseteq Y$ and $F$ be a closed set of $X$ such that $f^{-1}(S) \subseteq F$. Now $X-F$ is an open set in X. Since $f$ is RMG-open map, $f(X-F)$ is RMG-open set in $Y$. Then $T=Y-f(X-F)$ is a RMG-closed set in $Y$. Note that $\mathrm{f}^{-1}(\mathrm{~S}) \subseteq F$ implies $S \subseteq T$ and $\mathrm{f}^{-1}(\mathrm{~T})=\mathrm{X}-\mathrm{f}^{-1}(X-F) \subseteq X-(X-F)=F$. i.e. $\mathrm{f}^{-1}(T) \subseteq F$.

Conversely, suppose $\mathrm{U}$ be an open set of $\mathrm{X}$. Then $(\mathrm{Y}-\mathrm{f}(\mathrm{U})) \subseteq \mathrm{X}-\mathrm{U}$ is a closed set in $\mathrm{X}$. By hypothesis, there exists a RMG-closed set $T$ of $Y$ such that $Y-f(U) \subseteq T$ and $f^{-1}(T) \subseteq X-U$ and so $U \subseteq X-f^{-1}(T)$. Hence $Y-T \subseteq f(U) \subseteq Y-$ $f\left(f^{-1}(T) \subseteq Y-T\right.$ which implies $f(U)=Y-T$. Since $Y-T$ is a RMG-open, $f(U)$ is RMG-open in $Y$ and therefore $f$ is RMGopen map.

Theorem 4.12: If $\mathrm{f}: \mathrm{X} \rightarrow \mathrm{Y}$ is RMG-open, then $\mathrm{f}^{-1}(\mathrm{RMG}-\mathrm{cl}(\mathrm{A})) \subseteq \mathrm{cl}\left(\mathrm{f}^{-1}(\mathrm{~A})\right)$ for each subset $\mathrm{A}$ of $\mathrm{Y}$.

Proof: Let $f: X \rightarrow Y$ is a RMG-open map and $A$ be any subset of $Y$. Then $f^{-1}(A) \subseteq c l\left(f^{-1}(A)\right)$ and $\operatorname{cl}\left(f^{-1}(A)\right)$ is closed set in $\mathrm{X}$. Then by above Theorem 4.11, there exists a RMG-closed set $\mathrm{B}$ of $\mathrm{Y}$ such that $\mathrm{A} \subseteq \mathrm{B}$ and

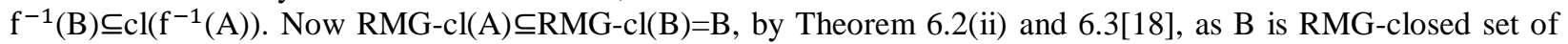
Y. Therefore $\mathrm{f}^{-1}(\mathrm{RMG}-\mathrm{cl}(\mathrm{A})) \subseteq \mathrm{f}^{-1}(\mathrm{~B})$ and so $\mathrm{f}^{-1}(\mathrm{RMG}-\mathrm{cl}(\mathrm{A})) \subseteq \mathrm{f}^{-1}(\mathrm{~B}) \subseteq \mathrm{cl}\left(\mathrm{f}^{-1}(\mathrm{~A})\right)$. Thus $\mathrm{f}^{-1}(\mathrm{RMG}$ $\mathrm{cl}(\mathrm{A})) \subseteq \mathrm{cl}\left(\mathrm{f}^{-1}(\mathrm{~A})\right)$ for each subset of $\mathrm{A}$ of $\mathrm{Y}$.

Theorem 4.13: If $\mathrm{f}: \mathrm{X} \rightarrow \mathrm{Y}$ is RMG-open, then for each neighbourhood $\mathrm{U}$ of $\mathrm{x}$ in $\mathrm{X}$, there exists a RMGneighbourhood $\mathbf{N}$ of $\mathrm{f}(\mathrm{x})$ in $\mathrm{Y}$ such that $\mathbf{N} \subseteq \mathrm{f}(\mathrm{U})$.

Proof: Let $\mathrm{f}: \mathrm{X} \rightarrow \mathrm{Y}$ is a RMG-open map. Let $\mathrm{x} \in \mathrm{X}$ and $\mathrm{U}$ be an arbitrary neighbourhood of $\mathrm{x}$ in $\mathrm{X}$. Then there exists an open set $G$ in $X$ such that $x \in G \subseteq U$. Now $f(x) \in f(G) \subseteq f(U)$ and $f(G)$ is RMG-open set in $Y$, as $f$ is RMG-open map. By Theorem 4.10 [18] $f(G)$ is RMG-neighbourhood of each of its points. By taking $f(G)=N$, Nis a RMG-nbd of $f(x)$ in $\mathrm{Y}$ such that $\mathbf{N} \subseteq \mathrm{f}(\mathrm{U})$.

Theorem 4.14: For any bijection map $\mathrm{f}: \mathrm{X} \rightarrow \mathrm{Y}$, the following statements are equivalent;

(i) $\mathrm{f}^{-1}: \mathrm{Y} \rightarrow \mathrm{X}$ is RMG-continuous.

(ii) $\mathrm{F}$ is RMG-open map.

(iii) $\mathrm{F}$ is RMG-closed map.

Proof: (i) $\Rightarrow$ (ii), let $U$ be an open set of $X$. By assumption, $\left(f^{-1}\right)^{-1}(U)=f(U)$ is RMG-open in $Y$ and so $f$ is RMGopen.

(ii) $\Rightarrow$ (iii), let $F$ be a closed set of $X, X-F$ is open set in $X$. By assumption, $f(X-F)$ is RMG-open in $Y$ i.e. $f(X-F)$ is RMG-open set in Y, since every open set is RMG-open Corollary 3.6(3)[18] and therefore $f(F)$ is RMG-closed in $Y$. Hence $\mathrm{f}$ is RMG-closed map. 
(iii) $\Rightarrow\left(\right.$ i), let $F$ be a closed set of $X$. By the assumption, $f(F)$ is RMG-closed in $Y$. But $f(F)=\left(f^{-1}\right)^{-1}(F)$ and therefore $\mathrm{f}^{-1}$ is continuous.

Remark 4.15: The composition of two RMG-open maps need not be a RMG-open map.

Now we define the new class of stronger form of RMG-open maps is called RMG*-open maps in topological spaces.

Definition 4.16: A map $f: X \rightarrow Y$ is said to be $\mathbf{R M G}$-open map, if the image $f(A)$ is $R M G$-open set in $Y$ for every RMG-open set $\mathrm{A}$ in $\mathrm{X}$.

Remark 4.17: Since every open set is a RMG-open set, we have every RMG*-open map is RMG-open map. The converse is not true generally as seen from the following example.

Example 4.18: Let $X=\{p, q, r\}$ with topology $\tau=\{X, \emptyset,\{q\},\{q, r\}\}$ and $Y=\{a, b, c, d\}$ with topology $\sigma=\{Y, \emptyset$, $\{a\},\{b, c\},\{a, b, c\}\}$. Let a map $f:(X, \tau) \rightarrow(Y, \sigma)$ be defined as $f(p)=b, f(q)=a$ and $f(r)=d$. Then $f$ is RMG-open map but not $\mathrm{RMG}^{*}$-open, since the image of $\mathrm{RMG}$-open set $\{\mathrm{q}, \mathrm{r}\}$ in $\mathrm{X}$ is $\{\mathrm{a}, \mathrm{d}\}$, which is not RMG-open in $\mathrm{Y}$. Hence $\mathrm{f}$ is not $\mathrm{RMG}^{*}$-open map.

Theorem 4.19: If $\mathrm{f}: \mathrm{X} \rightarrow \mathrm{Y}$ and $\mathrm{g}: \mathrm{Y} \rightarrow \mathrm{Z}$ be two $\mathrm{RMG}^{*}$-open maps, then their composition $\mathrm{g} \circ \mathrm{f}: \mathrm{X} \rightarrow \mathrm{Z}$ is $\mathrm{RMG}$-open map.

Proof: Proof is similar to the Theorem 3.54

Theorem 4.20: For any bijective map $\mathrm{f}: \mathrm{X} \rightarrow \mathrm{Y}$, the following statements are equivalent;

(i) $\mathrm{f}^{-1}: \mathrm{Y} \rightarrow \mathrm{X}$ is $\mathrm{RMG}$-irresolute map.

(ii) $\mathrm{f}$ is $\mathrm{RMG}^{*}$-open map.

(iii) $\mathrm{f}$ is $\mathrm{RMG}^{*}$-closed map.

Proof: Proof is similar to the Theorem 4.14.

\section{References:-}

1. Arockiarani, Studies on generalization of generalized closed sets and maps in topological spaces, Ph.D Thesis, Bharathiar University, Coimbatore, (1997)

2. S. S. Benchalli and R. S. Wali, On rw-closed sets on topological spaces, Bull. MalaysiaMath. Sci. Soc., 30(2007), 99-110.

3. El-Deeb, N. Hasanein, I. A. Noiri, T. and Mashhour, A.S. On P-regular spaces, Bull. Math. Soc. Sci. Math. R. S. Roumanie, 27(1983), 311-319.

4. N. Levine, Generalized closed sets in topology, Rend. Circ. Math. Palermo, 19(1970), 89-96.

5. P. E. Long and L. L. Heirington, Basic properties of regular closed functions, Rend. Cir. Math. Palermo, 27(1978), 20-28.

6. S. R. Malghan., Generalized closed maps, J. Karnataka Univ. Sci., 27(1982), 82-88.

7. H. Maki, R. Devi and K. Balachandran, Associated topologies of generalized $\alpha$-closed sets and $\alpha$-generalized closed sets, Mem. Sci. Kochi Univ.Ser. A. Math., 15(1994), 51-63.

8. A. S. Mashhour, M. E. Abd. El-Monsef and S. N. El-Deeb, On pre-continuous and mappings and weakly pre-continuous mappings, Proc. Math. Phy. Soc. Egypt, 53(1982), 47-53

9. N. Nagaveni, Studies on Generalizations of Homeomorphisms in Topological Spaces, Ph.D.Thesis, Bharathiar University, Coimbatore, 1999.

10. O. Njastad, On some classes of nearly open sets, Pacific J. Math., 15(1965), 961-970.

11. N. Palaniappan and K.C.Rao, Regular generalised closed sets, kyungpook math, J., 33(1993), $211-219$.

12. J.K. Park and J.H. Park, Mildly generalized closed sets, almost normal and mildly normal spaces, Chaos, Solitions and Fractals, 20(2004), 1103- 1111.

13. O. Ravi ${ }^{1 *}$. I. Rajasekaran ${ }^{1}$ and M. Sathyabama ${ }^{2}$, Weakly ${ }^{*}$-closed sets, International Journal of Current Research in Science and Technology, Volume1, Issue 5(2015), 45-52.

14. Ratnesh Kumar Saraf and Miguel Caldas, Between closed maps and g-closed maps, Bulletin of the Greek Mathematical Society Valume 53, 2007(135-146).

15. M. Sheik John, A study on generalizations of sets on continuous maps in topological and bitopological spaces, Ph.D. Thesis Bharathiar Univ., Coimbatore (2002).

16. M. Stone, Application of the theory of Boolian rings to general topology, Trans. Amer. Math. Soc., 41(1937), 374-481.

17. R. S. Wali, Nirani Laxmi, On Regular Mildly Generalized (RMG) Closed sets in topological spaces. International Journal of Mathematical Archive-7(7), 2016, 108-114. 
18. R. S. Wali, Nirani Laxmi, On Regular Mildly Generalized (RMG) Open Sets in Topological Spaces", IOSR Journal of Mathematics (IOSR-JM) e-ISSN: 2278-5728, p-ISSN: 2319-765X. Volume 12, Issue 4, Ver. IV (Jul.-Aug.2016), PP 93-100.

19. R. S. Wali, Nirani Laxmi and Basayya B. Mathad, On Regular Mildly Generalized (RMG) Continuous and irresolute functions in Topological Spaces", International Journal of Mathematics Trends and Technology-Paper ID- MTT6167. 